\title{
GÊNERO E TRABALHO DAS MULHERES PESCADORAS DOS REASSENTAMENTOS RURAIS NO EXTREMO NORTE DO TOCANTINS
}

Gender and Work of Fisherwomen of Rural Resettlements in Extreme Norlh of Tocantins

Género y Trabajo de pescadoras de los asentamientos rurales en el extremo norte Tocantins

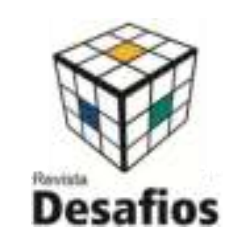

Artigo Original

Original Article Artículo Original

\section{Magna Marinho Ferreira ${ }^{*}$, Temis Gomes Parente ${ }^{1}$ \\ ${ }^{1}$ Curso de História, Fundação Universidade Federal do Tocantins (UFT), Porto Nacional, Brasil.}

*Correspondência: Rua 03, Quadra 17, Lote 11, s/n Setor Jardim dos Ipês. E-mail:

marinho.inteligente@hotmail.com

\section{Artigo recebido em 30/10/2015. Aprovado em 09/12/2015. Publicado em 24/02/2017.}

\section{RESUMO}

O presente trabalho tem como objetivo estudar as questões de gênero e trabalho das mulheres pescadoras dos reassentamentos rurais no extremo norte do Tocantins, criados com a construção da Hidrelétrica de Estreito, divisa do Tocantins com o Maranhão. O Estudo analisa a atividade profissional da pesca das mulheres impactadas pela construção da usina e procurar entender as questões de gênero vivenciadas por aquela população quando se refere à atividade pesqueira. Através das narrativas de mulheres e homens foi possível perceber que mesmo possuindo a carteira de pescadoras provisionais, nas falas das/os pesquisadas/os ocorre um reforço dos papeis de gênero.

Palavras-chave: Gênero; Trabalho; Pescadoras;

\section{ABSTRACT}

This work aims to study gender issues and work of fisherwomen of rural settlements in the north of Tocantins, created with the construction of the Estreito Hydroelectric, Tocantins border with Maranhão. The study analyzes the professional activity of fisherwomen impacted by the construction of the plant and looking to understand gender issues experienced by this population when it comes to fishing. Through the stories of women and men was revealed that despite having the portfolio of professional fishers, in the words of / the surveyed / it is a reinforcement of gender roles.

Keywords: Genre; Job; fisherwomen ;

\section{RESUMEN}

Este trabajo tiene como objetivo estudiar las cuestiones de género y el trabajo de las pescadoras de los asentamientos rurales en el extremo norte de Tocantins, creada con la construcción de la hidroeléctrica de Estreito, frontera Tocantins con Maranhão. El estudio analiza la actividad de pesca profesional de las mujeres afectadas por la construcción de la planta y tratar de comprender las cuestiones de género experimentadas por esta población cuando se trata de pesca. A través de las historias de las mujeres y los hombres se puso de manifiesto que a pesar de tener la cartera de pescadoras provisionales, en las palabras de / del / os encuestados es un refuerzo de los roles de género.

Palabras clave: Género; trabajar; pescadoras;

\section{INTRODUÇÃO}

Esta pesquisa se propõe a entender o trabalho das mulheres pescadoras dos reassentamentos rurais, criado com a construção da usina hidrelétrica de Estreito, abordando os principais impactos ocorridos na vida das mulheres pescadoras do extremo Norte do 
Tocantins. Pretende ainda entender o processo em que essas mulheres pescadoras tiveram quando foram atingidas pela construção da Hidrelétrica e como elas se adaptaram com todas as mudanças ocorridas com os impactos sofridos.

No rio Tocantins existe quatro hidrelétricas construídas, a Usina Hidrelétrica de Estreito que esta localizada entre os estados do Maranhão e Tocantins, a UHE Luis Eduardo Magalhães que esta localizada entre Lajeado e Porto Nacional, a UHE Peixe Angical que esta localizada em Peixe e a UHE São Salvador em Paranã, sendo que há três projetos em processo de licenciamento (Tupiratins, Ipueiras e Itaguatins), todas no rio Tocantins, além de um projeto no rio Araguaia (Santa Isabel).

O balanço sobre os impactos que estes projetos representaram para estas populações atingidas indicam que o processo não foi apenas injusto e desigual, mas, sobretudo trágico. Centenas de milhares de pessoas foram compulsoriamente deslocadas perdendo patrimônio material e imaterial acumulado por diversas gerações (SILVA, 2007).

Segundo Parente, (2007, p.102-103) essas grandes construções, como todo empreendimento de grande porte, geram impactos imediatos a médio e longo prazo no meio ambiente e nas sociedades tradicionais, ultrapassando os limites de sua abrangência. No que se refere aos discursos para justificar esses efeitos, no caso das construções das hidrelétricas, predomina o de levar o desenvolvimento às regiões antes atrasadas. Mas os problemas sociais e ambientais advindos com a construção da UHE Luís Eduardo Magalhães são mais amplos do que se imagina.
Embora as mulheres estejam presentes a todos os níveis e em algumas áreas, o seu papel no setor da pesca, até pouco tempo passou quase que completamente despercebido. Acredita-se que o fato de existir certo preconceito em relação à mulher pescadora, e que e possível entender que não é de hoje que este preconceito esta presente, o que se percebe é que a mulher esta deixando no passado idéias de que elas são frágeis e reportando no presente a importância do seu papel dentro das atividades que lhes são atribuídas (Leitão, 2008).

Neste contexto, a realidade é que se ser mulher é desvalorizado, ser mulher negra ou pescadora, o é ainda mais em um universo masculino. Na profissão de pescadora, a relação entre homens e mulheres repete o que ocorre no resto da sociedade: mesmo se esforçando como pescadoras as mulheres não tem o seu trabalho valorizado. Por isso, muitas vezes, elas próprias não conseguem enxergar a importância de seu papel! (Lima. Leitão, 2008 p.54).

\section{MATERIAIS E MÉTODOS}

A pesquisa privilegia a fonte oral, e seu tema remete a estudos que consideram sobremaneira as manifestações das massas anônimas, o cotidiano, a micro-história, os espaços informais e a cultura popular, neste caso estão incluídas as mulheres pescadoras atingidas pela construção da UHE. A história oral, além de expressar a historicidade da experiência pessoal e o papel do indivíduo na história da sociedade, permite ampliar os conhecimentos e as informações sobre um passado recente através da versão de pessoas que o viveram (Portelli, 1997, p. 14).

Neste contexto da historia oral é possível perceber que em uma região como o Tocantins onde 
são poucas as fontes documentais escritas sobre a figura da mulher, a historia oral tem sido um método bastante utilizado como uma forma de fazer com que se reconstituam as experiências e lutas cotidianas vividas, que segundo Portelli (1997), é como uma arte do indivíduo que leva ao reconhecimento não só da diferença, como também da igualdade. $\mathrm{Na}$ busca pela diferença, não podemos nos esquecer de que também acalentamos um sonho de compartilhar, de participar, de comunicar-nos e de dialogar (Portelli, 1997).

Nesta pesquisa, além de escolher trabalhar com a fonte oral, optou-se pela história de vida, que induz o entrevistado a contar livremente a sua vida, imprimindo à narrativa suas próprias categorias, ordenamento e a seleção do que quer falar (Lang, 2001, p.96). A história de vida é a expressão não da individualidade ou da singularidade, mas de uma determinada inserção social. Assim, ao ouvir as vozes das mulheres reassentadas, apreende-se a visão e/ou vivência de atores sociais, com base em sua posição na estrutura social - a mesma posição da maioria dos antigos moradores das margens do rio Tocantins, antes da formação do lago.

\section{RESULTADOS E DISCUSSÃO}

Foram realizadas 6 (seis) entrevistas com os presidentes das associações de pescadores de Estreito $^{1}$, e 4 entrevistas com as pescadoras(es) do acampamento Ilha $\operatorname{Verde}^{2}$, sendo que em cada

\footnotetext{
${ }^{1} \mathrm{Sr}^{\circ}$. Luiz Abreu de Moura, de Babaçulândia, $\mathrm{Sr}^{\mathrm{a}}$. Maria do Amparo Teles da Silva, de Filadélfia, $\mathrm{Sr}^{\circ}$. Alfeu Barbosa Maranhão, de Tocantinopólis, $\mathrm{Sr}^{\circ}$. João Aroldo Gomes de Almeida, de Palmeiras, $\mathrm{Sr}^{\circ}{ }^{\circ}$ Emiliano Dias Carneiro e com a $\mathrm{Sr}^{\mathrm{a}}$. Valderice Pereira da Silva que faz parte do MAB ( movimento dos atingidos por Barragens).

2 O Acampamento Ilha Verde no município de Babaçulândia, foi desmembrado por algumas famílias atingidos pela Hidrelétrica que inicialmente estavamacampados próximo a Estreito. O objetivo é
}

entrevista foi discutidos as questões de gênero e o papel da mulher durante as atividades na pesca, havendo assim um discurso em que, quando se perguntava para os presidentes das colônias sobre o papel da mulher era relatado que elas possuíam um papel de pescadora e não de ajudante, mas quando se refere a esta questão é possível perceber que a mulher pescadora possui nada mais do que tarefas consideradas leves pois na hora da pratica elas ficam de fora, ou seja elas ficam nos acampamentos fazendo os trabalhos domésticos.

Após as leituras e pesquisas que foram realizadas foi possível obter mais informações e conhecimento em relação ao tema da pesquisa. No processo de visita ao reassentamento foi possível entender como as famílias que foram atingidas vivem, sendo que foi feito um levantamento das associações de pescadores existentes e da quantidade de mulheres que fazem parte desses reassentamentos além de entender ainda mais sobre como é o cotidiano das pecadoras (es) daquela região. Ao obter esses dados foi de fundamental importância para desenvolvimento de toda a pesquisa.

\section{CONCLUSÃO}

Através desta pesquisa foi possível perceber que ao falar sobre as atividades das mulheres pescadoras é possível ver que ainda há uma certa invisibilidade, uma vez que nos papéis de gênero elas não são vistas como capazes para exercer as funções da pesca, além de muitas dessas mulheres sofreram com as mudanças trazidas pelas hidrelétricas.

conseguir a posse definitiva dos lotes da terras. As pessoas entrevistadas foram $\mathrm{Sr}^{\circ}$ José Ferreira de Sousa, Sra Euglene Gomes da Costa, $\mathrm{Sr}^{\mathrm{a}}$ Aparecida Alves da Silva Santos e a $\mathrm{Sr}^{\mathrm{a}}$ Jucilene Ribeiro da Conceição 


\section{AGRADECIMENTO}

"O presente trabalho foi realizado com o apoio do Conselho Nacional de Desenvolvimento Científico e Tecnológico - CNPq - Brasil"

Todos os autores declararam não haver qualquer potencial conflito de interesses referente a este artigo.

\section{REFERÊNCIAS}

LANG, Alice Beatriz da Silva. História oral: procedimentos e possibilidades. In: LANG, Alice Beatriz da Silva (org.). Desafios da pesquisa em Ciências Sociais. São Paulo: CERU, 2001.

PARENTE, Temis Gomes. Gênero e desempoderamento de mulheres, nos reassentamentos rurais da usina hidrelétrica de estreito, Tocantins. 2014.

PORTELLI, Alessandro. História Oral como gênero. In. Revista do programa de Estudos PósGraduação em História - Departamento de História PUC-SP. São Paulo: EDUC, 1997.

SILVA, Alexandra Martins. Mulheres em movimento: Luta e Resistência Contra Barragens. Coimbra, 2007. 